\title{
Pengaruh Jaringan Sosial, Kreativitas, Pengetahuan Pasar Kewirausahaan, Dan Alertness Terhadap Peluang Usaha
}

\author{
Anastasia Delicia dan Sarwo Edy Handoyo \\ Program Studi Manajemen Fakultas Ekonomi Universitas Tarumanagara, Jakarta \\ Email: anastasya_delicia@yahoo.com
}

\begin{abstract}
The purpose of this research is to know the impact of social networks, creativity, market entrepreneurship knowledge and alertness on business opportunities of tarumanagara university student. This study uses a sampling method is a non-probability sampling with the number of samples taken in the study were 150 respondents Tarumanagara University Faculty of Economics student. Data analysis method uses SEM (Structural Equation Modeling) with the SmartPLS program. The results of this study indicate that there are influences of social networks, creativity, entrepreneurial market knowledge, and alertness to business opportunities.
\end{abstract}

Keywords: social networks, creativity, market entrepreneurship knowledge alertness, and business opportunities.

Abstrak: Tujuan penelitian ini adalah untuk mengetahui pengaruh jaringan sosial, kreativitas, pengetahuan pasar kewirausahaan, dan alertness terhadap peluang usaha mahasiswa Ekonomi Universitas Tarumanagara. Penelitian ini menggunakan metode pengambilan sampel adalah non-probability sampling dengan jumlah sampel yang diambil dalam penelitian ialah 150 responden mahasiswa Fakultas Ekonomi Universitas Tarumanagara. Metode analisis data menggunakan SEM (Structural Equation Modelling) dengan program SmartPLS. Hasil penelitian ini menunjukan terdapat pengaruh jaringan sosial, kreativitas, pengetahuan pasar kewirausahaan, dan alertness terhadap peluang usaha.

Kata Kunci: Jaringan sosial, kreativitas, pengetahuan pasar kewirausahaan, alertness dan peluang usaha.

\section{LATAR BELAKANG}

Pertumbuhan penduduk masyarakat di Indonesia yang semakin pesat, menimbulkan sebuah persaingan yang begitu ketat dalam menemukan lapangan kerja untuk memenuhi kebutuhan hidup sehari-hari. Hal inilah yang memicu pengangguran yang semakin meningkat. Sedikitnya masyarakat Indonesia membuka usahanya sendiri karena tidak dapat melihat peluang disekitar lingkungannya dan faktor-faktor lainnya. Menurut (Sunyoto, 2013), peluang adalah kesempatan yang harus diambil oleh seseorang wirausaha untuk mewujudkan atau melaksanakan suatu usaha dengan keberanian mengambil risiko. Peluang dapat muncul melalui pemikiran, teman, lingkungan, hasil pengamatan, ide, hobi, kreativitas, membaca majalah, internet, koran. 
Terdapat faktor-faktor yang mempengaruhi peluang usaha, namun dalam penelitian ini dibatasi hanya empat variabel yaitu jaringan sosial, kreativitas, pengetahuan pasar kewiraushaan, dan alertness. Variabel tersebut berkaitan erat dengan bagaimana seseorang melihat peluang usaha untuk menjadikan hal tersebut kunci memiliki usaha jangka panjang atau jangka pendek.

Menurut Indarti et al. (2011) menyatakan bahwa wirausaha membutuhkan jaringan sosial yang kuat selain modal, informasi, keterampilan, tenaga kerja untuk memulai usaha. Namun, (Porter et al, 2011), menyatakan bahwa informasi yang diterima dari media sosial dapat berdampak negatif pada penemuan peluang wirausaha harus berdasarkan pengetahuan dan pengalaman sebelumnya.

(Heinonen et al, 2011) menyatakan bahwa kreativitas memiliki dampak yang positif terhadap strategi dalam mencari peluang bisnis. Seseorang yang ingin mengembangkan kreativitasnya dalam berwirausaha akan cenderung melakukan strategi-strategi mencari peluang bisnis.

(Cardon et al, 2009) menyebutkan bahwa kreativitas diperlukan untuk menemukan peluang bisnis, tetapi itu tidak cukup untuk inovasi karena banyak ide kreatif tidak dapat dipasarkan atau tidak dapat dikembangkan oleh orang-orang yang menghasilkan ide kreatif.

(Grégoire et al, 2010) menganggap pengetahuan pasar kewirausahaan sebagai sumber daya kognitif dari individu dan landasan proses identifikasi peluang. Sebaliknya, sebuah studi oleh (Chandra et al, 2009) mengemukakan bahwa pengetahuan kewirausahaan tidak cukup, tetapi harus digabungkan dengan informasi lain dari berbagai sumber, seperti pendidikan dan koneksi sosial, yang membantu orang dalam mengenali, menemukan, dan menciptakan peluang.

(Hou, 2008) mengatakan bahwa individu dengan kewirausahaan alertness yang kuat lebih mungkin mengidentifikasi peluang yang memainkan peran penting dalam mengembangkan usaha baru.

Masalah penelitian ini adalah bagaimana keterkaitan antara konsep jaringan sosial, kreativitas, pengetahuan pasar kewiraushaan dan alertness terhadap peluang usaha. Hal ini bertujuan agar saat Mahasiswa Fakultas Ekonomi Universitas Tarumanagara telah lulus dan terjun langsung ke masyarakat, mereka memiliki ilmu dan mental menjadi entrepreneur. Berdasarkan latar belakang yang ada di atas, penelitian ini difokuskan untuk mengetahui dan menganalisis "Pengaruh jaringan sosial, kreativitas, pengetahuan pasar kewiraushaan dan alertness terhadap peluang berwirausaha mahasiswa Fakultas Ekonomi Universitas Tarumanagara"

\section{KAJIAN TEORI}

Definisi umum tentang peluang usaha menurut Suhartini (2011) peluang adalah kesempatan usaha yang dimiliki seseorang untuk melakukan apa yang dinginkannya atau yang menjadi harapannya. Menurut Hunter (2013) peluang bergantung pada individu yang mengenal, menemukan atau membangun pola dan konsep yang dapat dibentuk menjadi ide dan dihasilkan intuisi, visi, wawasan, penemuan, atau penciptaan adalah sebuah ide yang mungkin pada evaluasi menjadi peluang.

Menurut Suryana dan Bayu (2013), seorang wirausaha tidak dapat hidup sendiri dalam menjalankan usahanya, namun ada keterkaitan dengan pihak luar, baik sebagai pemasok, pelanggan, maupun pedagang perantara. Oleh karena itu, diperlukan suatu jaringan usaha agar usaha yang kita jalankan berkelanjutan. 
Kreativitas menurut Zimmerer, Scarborough, dan Wilson (2008), kreativitas adalah "kemampuan untuk mengembangkan ide-ide baru dan untuk menemukan cara-cara baru untuk melihat masalah dan kesempatan". Dengan kreativitas, seorang entrepreneur mampu menampilkan inovasi, yaitu "kemampuan untuk mengaplikasikansolusi kreatif terhadap masalah dan peluang untuk meningkatkan atau mengembangkan kehidupan seseorang".

Menurut Widding, (2005) menyatakan bahwa "pengetahuan kewirausahaan dapat didefinisikan sebagai pengetahuan multifungsi yang terdiri dari produk, pasar, organisasi dan pendanaan. Dapat diasumsikan bahwa pengusaha tidak secara pribadi memegang semua "pengetahuan bisnis yang diperlukan untuk mendapatkan keunggulan kompetitif".

Menurut Gaglio dan Katz, (2001) setiap orang yang memiliki kemampuan alertness yang tinggi akan menjadi sadar terhadap sesuatu yang terjadi di lingkungan pasar dan mampu mengidentifikasi kekuatan penggerak dan elemen kunci di dalam hubungan tersebut. Chang (2014), juga memperkuat bahwa adanya persepsi akan mempengaruhi perhatian dan cara mengelolah informasi yang kemudian menjadi lebih nyata dengan sinyal yang muncul dari informasi diluar lingkungan. Orang dengan alertness tinggi membuat orang-orang tersebut peka terhadap level ekonomi yang tidak seimbang.

Kerangka penelitian dalam penelitian ini dapat disajikan Gambar 1 sebagai berikut:

\section{Gambar 1.}

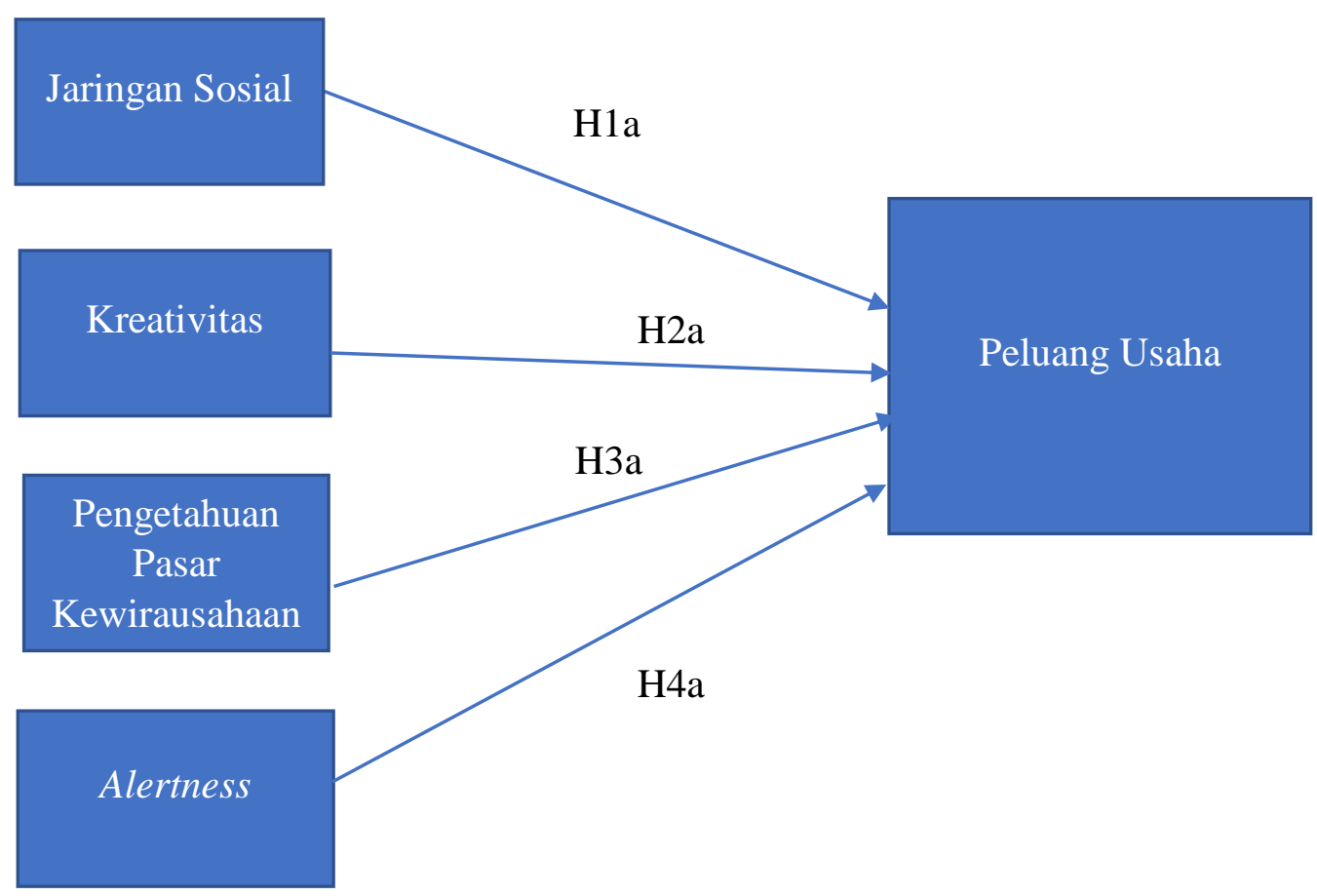

Dengan hipotesis sebagai berikut:

H1a : Terdapat pengaruh positif antara jaringan sosial dengan peluang usaha.

$\mathrm{H} 2 \mathrm{a}$ : Terdapat pengaruh positif antara kreativitas dengan peluang usaha.

$\mathrm{H} 3 \mathrm{a}$ : Terdapat pengaruh positif antara pengetahuan pasar kewiraushaan 
dengan peluang usaha

$\mathrm{H} 4 \mathrm{a}$ : Terdapat pengaruh positif antara alertness dengan peluang usaha.

\section{METODOLOGI}

Penelitian ini merupakan penelitian kuantitatif dengan desain penelitian kausal. Subjek penelitian hasil penelitian ini didapatkan dari pembagian kuisioner kepada 150 mahasiswa Fakultas Ekonomi Universitas Tarumanagara. Pemilihan sampel dalam penelitian ini dilakukan secara tidak acak (non-probability sampling) dengan tipe pengambilan sampel purposive sampling.

Variabel operasional dalam penelitian ini terdiri dari jaringan sosial, kreativitas, pengetahuan pasar kewirausahaan dan alertness yang merupakan variabel independen, peluang usaha sebagai variabel dependen. Peluang usaha diukur dengan indikator yang diadopsi dari penelitian sebelumnya \, indikator dari jaringan sosial indikator kreativitas, indikator pengetahuan pasar kewirausahaan, dan indikator dalertness.

Berdasarkan data yang didapat dari $150(100 \%)$ responden, sebanyak $88(58,7 \%)$ responden berjenis kelamin laki-laki dan $62(41,3 \%)$ responden berjenis kelamin perempuan. Semua responden yang menjawab kuisioner merupakan mahasiswa Ekonomi Universitas Tarumanagara. Penelitian ini menggunakan skala Likert sebagai pemberian skor dari setiap indikator dan penyebaran kuisioner dilakukan secara online melalui internet dengan menggunakan Google Form. Malhotra (2015:308) mengemukakan bahwa skala Likert merupakan kategori pendapat para responden yang diukur dengen tingkat setuju atau tidak setuju pada rangkaian pernyataan atau pertanyaan yang terdapat dalam kuisioner yang telah dibuat.

Hasil Uji Statistik. Hair et al. (2011) maupun Henseler et al. (2009) menyatakan bahwa uji validitas dapat dilakukan dengan cara mengevaluasi convergent validity dan discriminant validity dalam model penelitian tersebut. Convergent validity diuji dengan menggunakan loading factor dari setiap indikator dan average extracted variance (AVE) dari setiap variabel.

Tabel 1. Hasil Nilai Average Variance Extracted (AVE)

\begin{tabular}{|c|c|}
\hline Variabel & $\begin{array}{c}\text { Averange Variance Extracted } \\
\text { (AVE) }\end{array}$ \\
\hline Jaringan Sosial & 0,677 \\
\hline Kreativitas & 0,702 \\
\hline $\begin{array}{c}\text { Pengetahuan Pasar } \\
\text { Kewiraushaan }\end{array}$ & 0,589 \\
\hline Alertness & 0,599 \\
\hline Peluang Usaha & 0,636 \\
\hline
\end{tabular}


Hasil dari AVE menunjukkan nilai sebesar 0,677 untuk variabel jaringan sosial, 0,702 untuk variabel kreativitas, 0,589 untuk variabel pengetahuan pasar kewirausahaan, 0,599 untuk variabel alertness dan 0,636 untuk peluang usaha. AVE memiliki nilai yang lebih besar dibanding nilai korelasi antara variabel potensial yaitu dengan minimal sebesar 0,5 maka berarti telah mencapai nilai discriminant validity (Henseler et al, 2009). Selanjutnya, suati indikator dinyatakan valid jika mempunyai loading factor diatas 0,7 terhadap konstruk yang dituju.

Tabel 2. Hasil Nilai Loading Factor

\begin{tabular}{|c|c|c|}
\hline \multicolumn{2}{|r|}{ Indikator } & Loading Factor \\
\hline PU1 & $\begin{array}{l}\text { Saya mampu untuk mengidentifikasi produk dan layanan yang } \\
\text { memenuhi keinginan pelanggan }\end{array}$ & 0,831 \\
\hline PU2 & Saya mampu untuk menemukan produk yang menguntungkan & 0,769 \\
\hline PU3 & $\begin{array}{l}\text { Saya mampu untuk mengembangkan cara agar dapat memenuhi } \\
\text { kebutuhan pelanggan yang belum terpenuhi }\end{array}$ & 0,768 \\
\hline PU4 & $\begin{array}{l}\text { Sebelum perkenalan produk dan layanan baru, saya sudah } \\
\text { mengetahui siapa target pelanggan saya sebenarnya. }\end{array}$ & 0,819 \\
\hline JS1 & $\begin{array}{l}\text { Saya sering menggunakan media sosial untuk mendapatkan informasi } \\
\text { dan pengetahuan yang berhubungan dengan pekerjaan }\end{array}$ & 0,854 \\
\hline JS2 & $\begin{array}{l}\text { Saya dapat memperoleh banyak pengetahuan dari kontak / pelanggan } \\
\text { dalam sistem jaringan sosial }\end{array}$ & 0,785 \\
\hline JS3 & Saya menggunakan media sosial untuk menghubungi pelanggan & 0,825 \\
\hline JS4 & $\begin{array}{l}\text { Saya menggunakan media sosial untuk menjalin dan memperkuat } \\
\text { komunikasi di lingkungan kerja }\end{array}$ & 0,825 \\
\hline K1 & Saya mampu berpikir kreatif & 0,906 \\
\hline $\mathrm{K} 2$ & Saya mempunyai ide-ide kreatif untuk membangun usaha & 0,797 \\
\hline K3 & Saya melakukan cara-cara baru untuk mengembangkan peluang usaha & 0,865 \\
\hline K4 & $\begin{array}{l}\text { Saya mampu memberikan nilai,tambah (added value) yang } \\
\text { membedakan produk yang saya hasilkan berbeda dengan orang lain }\end{array}$ & 0,778 \\
\hline PPK1 & Saya mengumpulkan informasi terkait dengan usaha yang saya kelola & 0,643 \\
\hline PPK2 & $\begin{array}{l}\text { Sebelum memulai usaha, saya mengetahui cara membuat pelanggan } \\
\text { ingin menggunakan produk yang saya buat }\end{array}$ & 0,830 \\
\hline PPK3 & $\begin{array}{l}\text { Sebelum memulai usaha, saya telah memiliki kedekatan (engaged) } \\
\text { dengan produk dan pengalaman mengelola layanan ke konsumen }\end{array}$ & 0,767 \\
\hline PPK4 & $\begin{array}{l}\text { Pengalaman kerja saya sebelumnya bermanfaat untuk memulai usaha } \\
\text { yang saya bangun }\end{array}$ & 0,816 \\
\hline A1 & $\begin{array}{l}\text { Saya sering berinteraksi dengan orang lain untuk mendapatkan } \\
\text { informasi baru }\end{array}$ & 0,803 \\
\hline A2 & Saya mengenali peluang saat mengerjakan tugas-tugas lain & 0,826 \\
\hline
\end{tabular}




\begin{tabular}{|l|l|c|}
\hline A3 & $\begin{array}{l}\text { Saya mempergunakan waktu luang saya untuk memikirkan segala } \\
\text { masalah yang dapat terjadi dikemudian hari jika saya menjadi } \\
\text { wirausaha }\end{array}$ & 0,703 \\
\hline A4 & $\begin{array}{l}\text { Saya bisa membedakan antara peluang yang menguntungkan dan } \\
\text { yang tidak menguntungkan }\end{array}$ & 0,760 \\
\hline
\end{tabular}

Sumber : olahan data Smart-PLS versi 3.00

Berdasarkan hasil dari Tabel 2, telah menunjukkan bahwa seluruh indikator memiliki nilai loading factor di atas 0,6 di mana telah memenuhi syarat convergent validity (Hair et $a l ., 2011$ ), sehingga dapat disimpulkan bahwa semua variabel yang ada dalam penelitian ini telah memenuhi kriteria convergent validity.

Tabel 3. Hasil Pengujian Reliabilitas

\begin{tabular}{|c|c|c|}
\hline Variabel & Cronbach's Alpha & $\begin{array}{c}\text { Composite } \\
\text { Reliability (CR) }\end{array}$ \\
\hline Jaringan Sosial & 0,841 & 0,893 \\
\hline Kreativitas & 0,858 & 0,904 \\
\hline $\begin{array}{c}\text { Pengetahuan Pasar } \\
\text { Kewiraushaan }\end{array}$ & 0,762 & 0,850 \\
\hline Alertness & 0,778 & 0,856 \\
\hline Peluang Usaha & 0,809 & 0,875 \\
\hline
\end{tabular}

*Sumber : olahan data Smart-PLS versi 3.00

Berdasarkan hasil pengujian reliabilitas pada tabel 3, diketahui bahwa variabel di atas memiliki nilai cronbach's alpha dan composite realibility di atas 0,7 . Dengan nilai tersebut, maka dapat disimpulkan bawa data pada penelitian ini reliabel karena memenuhi kriteria dengan hasil yang berada di atas 0,7 (Hair et al., 2011).

Setelah pengujian outer model (validitas dan reliabilitas), pengolahan data variabelvariabel penelitian dilanjutkan pada tahapan pengujian inner model (model struktural) untuk dapat mengetahui kontribusi dari variabel-variabel independen $(\mathrm{X})$ terhadap variabelvariabel dependen (Y). Kriteria pengujian model struktural yang harus dipenuhi pada penelitian ini yaitu nilai koefisien determinasi $\left(\mathrm{R}^{2}\right)$ dan path coefficients.

Hasil nilai koefisen determinasi $\left(\mathrm{R}^{2}\right)$ pada penelitian ini adalah sebesar 0,715 , berarti $71,5 \%$ dari variabel dependen yaitu peluang usaha dapat dijelaskan oleh variabel independen yang terdapat pada penelitian ini dan sisanya yaitu sebesar $28,5 \%$ dapat dijelaskan oleh variabel-variabel yang tidak termasuk dalam penelitian ini. Berdasarkan kriteria nilai RSquare yang dikemukakan oleh Sarstedt, Ringle \& Hair (2017:20), pengujian koefisien determinasi mempunyai 3 kriteria yang diantaranya adalah jika nilai R Square 0,25 maka dikategorikan lemah. Jika nilai R Square 0,50 maka dapat dikategorikan sedang dan apabila nilai R Square 0,75 maka dapat dikategorikan kuat. 
Tabel 3. Hasil Pengujian Hipotesis

\begin{tabular}{|c|c|c|c|c|c|}
\hline & $\begin{array}{c}\text { Original } \\
\text { Sample } \\
(\mathrm{O})\end{array}$ & $\begin{array}{c}\text { Sample } \\
\text { Mean } \\
(\mathrm{M})\end{array}$ & $\begin{array}{c}\text { Standard } \\
\text { Deviation } \\
(\text { STDEV })\end{array}$ & $\begin{array}{c}\text { T Statistic } \\
(|\mathrm{O} / \mathrm{STDEV}|)\end{array}$ & $\begin{array}{c}\mathrm{P} \\
\text { Values }\end{array}$ \\
\hline $\begin{array}{c}\text { Jaringan Sosial } \rightarrow \\
\text { Peluang Usaha }\end{array}$ & 0,314 & 0,315 & 0,051 & 6,138 & 0,001 \\
\hline $\begin{array}{c}\text { Kreativitas } \rightarrow \\
\text { Peluang Usaha }\end{array}$ & 0,253 & 0,252 & 0,099 & 2,533 & 0,000 \\
\hline $\begin{array}{c}\text { Pengetahuan Pasar } \\
\text { Kewiraushaan } \rightarrow \\
\text { Peluang Usaha }\end{array}$ & 0,144 & 0,146 & 0,036 & 3,960 & 0,042 \\
\hline $\begin{array}{c}\text { Alertness } \rightarrow \\
\text { Peluang Usaha }\end{array}$ & 0,253 & 0,257 & 0,053 & 4,811 & 0,001 \\
\hline
\end{tabular}

*Sumber : olahan data Smart-PLS versi 3.00

Berdasarkan hasil diatas maka dapat dijelaskan hipotesis sebagai berikut :

$\mathrm{Ha}_{1}$ : Uji pengaruh jaringan sosial terhadap peluang usaha.

Berdasarkan hasil pengujian yang telah dilakukan pada setiap variabel, variabel X1 (jaringan sosial) terhadap Y (peluang usaha) memiliki nilai $t$-statistics sebesar 6,138, dan $P$ values sebesar 0,001 dimana hal tersebut menandakan bahwa $\mathrm{Ha}_{1}$ tidak ditolak karena nilai $t$-statistics lebih besar dari 1,96 dan $P$ value kurang dari 0,05. Dari hasil penelitian di atas dapat disimpulkan bahwa jaringan sosial memiliki pengaruh secara langsung terhadap peluang usaha mahasiswa di Universitas Tarumanagara.

$\mathrm{Ha}_{2}$ : Uji pengaruh kreativitas terhadap peluang usaha.

Berdasarkan hasil pengujian yang telah dilakukan pada setiap variabel, variabel X2 (kreativitas) terhadap $\mathrm{Y}$ (peluang usaha) memiliki nilai $t$-statistics sebesar 2,533 dan $P$ values sebesar 0,000 dimana hal tersebut menandakan bahwa $\mathrm{Ha}_{2}$ tidak ditolak karena nilai $t$-statistics lebih besar dari 1,96 dan $P$ value kurang dari 0,05. Dari hasil penelitian di atas dapat disimpulkan bahwa kreativitas memiliki pengaruh secara langsung terhadap peluang usaha mahasiswa di Universitas Tarumanagara.

Ha3: Uji pengaruh kreativitas terhadap peluang usaha.

Berdasarkan hasil pengujian yang telah dilakukan pada setiap variabel, variabel X3 (pengetahuan pasar kewiraushaan) terhadap Y (peluang usaha) memiliki nilai $t$-statistics sebesar 3,960 dan $P$ values sebesar 0,042 dimana hal tersebut menandakan bahwa $\mathrm{Ha}_{3}$ tidak ditolak karena nilai $t$-statistics lebih besar dari 1,96 dan $P$ value kurang dari 0,05. Dari hasil penelitian di atas dapat disimpulkan bahwa pengetahuan pasar kewiraushaan memiliki pengaruh secara langsung terhadap peluang usaha mahasiswa di Universitas Tarumanagara.

Ha4: Uji pengaruh kreativitas terhadap peluang usaha.

Berdasarkan hasil pengujian yang telah dilakukan pada setiap variabel, variabel X4 (alertness) terhadap Y (peluang usaha) memiliki nilai $t$-statistics sebesar 4,811 dan $P$ values 
sebesar 0,001 dimana hal tersebut menandakan bahwa $\mathrm{Ha}_{4}$ tidak ditolak karena nilai $t$ statistics lebih besar dari 1,96 dan $P$ value kurang dari 0,05. Dari hasil penelitian di atas dapat disimpulkan bahwa alertness memiliki pengaruh secara langsung terhadap peluang usaha mahasiswa di Universitas Tarumanagara.

\section{DISKUSI}

Dari analisis data yang telah dilakukan, pengujian pada penelitian ini telah menghasilkan hasil yang sesuai dengan hipotesis. Hasil dari pengujian hipotesis menunjukkan terdapat pengaruh yang signifikan antara jaringan sosial, kreativitas, pengetahuan pasar kewirausahaan, dan alertness terhadap peluang usaha.

\section{PENUTUP}

Berdasarkan hasil penelitian dari pengujian data dalam penelitian ini menunjukkan bahwa jaringan sosial, kreativitas, pengetahuan pasar kewirausahaan, dan alertness terhadap peluang usaha mahasiswa Fakultas Ekonomi Universitas Tarumanagara. Dalam sebuah penelitian tentunya dapat memiliki beberapa keterbatasan, begitu pula dalam penelitian ini. Keterbatasan dari penelitian ini dikarenakan: 1) Variabel yang diteliti dalam penelitian ini masih terbilang cukup terbatas yaitu hanya pada dua variabel bebas, satu variabel terikat, dan satu variable mediasi 2) Sehubungan dengan waktu yang relatif singkat maka penelitian hanya dapat melibatkan sebagian kecil dari mahasiswa Universitas Tarumanagara. 3) Selain itu, karena menggunakan kuesioner yang disebar secara online melalui internet, maka terkadang jawaban yang diberikan oleh para responden tidak dijawab secara jujur dan tidak menunjukkan keadaan yang semestinya.

Berdasarkan hasil dan keterbatasan di atas, maka saran yang dapat diberikan untuk melakukan penelitian selanjutnya adalah 1) peneliti memberikan saran untuk memperbanyak jangkauan pengambilan sampel, sehingga akan memperkuat penelitian yang akan dilaksanakan berikutnya dan dapat memperkuat penelitian yang sudah dilakukan sebelumnya. 2) disarankan untuk meneliti variabel-variabel lain di luar variabel yang telah digunakan dalam penelitian ini sehingga dapat mengetahui faktor-faktor yang dapat mempengaruhi peluang usaha.

\section{DAFTAR PUSTAKA}

Cardon, M.S., Wincent, J., Sing, J., Drnvosek, M. . (2009). The nature and experience of entrepreneurial passion. 511-532. https://doi.org/10.4337/9781783479801.00014

Chandra, Y., Styles, C., \& Wilkinson, I. (2009). The recognition of first time international entrepreneurial opportunities. $\quad 56(4), \quad 198-204$. https://doi.org/10.1179/str.2009.56.4.005

Chang, W.L., Liu, W.G.H., dan Chiang, S. M. (2014). A Study of the Relationship between Entrepreneurship Courses and Opportunity Identification: An Empirical Survey. 124.

Gaglio, C. M., \& Katz, J. A. (2001). The psychological basis of opportunity identification: entrepreneurial alertness. Small Business Economics. 95-112. 
Grégoire, D. A., Barr, P. S., \& Shepherd, D. A. (2010). Cognitive Processes of Opportunity Recognition: The Role of Structural Alignment. 413-431.

Hair, J. F., Ringle, C. M., \& Sarstedt, M. (2011). PLS-SEM: Indeed a Silver Bullet. Journal of Marketing Theory and Practice, 19(2), 139-152.

Heinonen, J., Hytti, U., \& Stenholm, P. (2011). The role of creativity in opportunity search and business idea creation. Education + Training, 53(8-9), 659-672. https://doi.org/10.1108/00400911111185008

Henseler, J., Ringle, C. M., \&amp; Sinkovics, R. R. (2009). The use of partial least square path modeling in International Marketing. Advances in International Marketing, 20, 277-319.

Hou, S. T. (2008). Antecedents and consequence of entrepreneurial alertness in franchise chain. Journal of International Business Research and Marketing, 166-171. https://doi.org/10.18775/jibrm.1849-8558.2015.16.3001

Hunter, M. (2013). "A Typologi of Entrepreneurial Opportunity". Economics, Management \& Financial Markets Journal. 128-166.

Indarti, N., \& Rostiani, R. (2011). Undergraduate student's entrepreneurial intention: A comparative study among Indonesia, Japan and Norway. Journal of Indonesian Economy and Business, 23(4), 369-384. https://doi.org/10.22146/jieb.6316

Porter, C. E., Donthu, N., MacElroy, W. H., \& Wydra, D. (2011). (2011). How to Foster and Sustain Engagement in Virtual Communities. Mankind, 13(3), 80-110. https://doi.org/10.1111/j.1835-9310.1982.tb01239.x

Suhartini, Y. (n.d.). Analisis faktor-faktor yang mempengaruhi minat mahasiswa dalam berwiraswasta (studi pada mahasiswa Universitas PGRI Yogyakarta). Jurnal Akuntansi Dan Manajemen.

Sunyoto, D. (2013). Dasar-Dasar Manajemen Pemasaran. Yogyakarta: CAPS.

Suryana, Y., \& Bayu, K. (2013). Kewirausahaan: Pendekatan Karakteristik Wirausahawan Sukses.

Zimmerer, T.W, Scarborough, N. . dan W. D. (2008). Kewirausahaan dan Manajemen Usaha Kecil.

Widding, Lars Øystein, 2005. "Building Entrepreneurial Knowledge Reservoirs”, Journal of Small Business and Enterprise Development, Volume 12 Nomor 4 hal 595-598. 